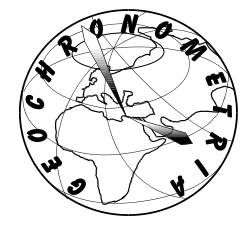

Conference Proceedings of the $12^{\text {th }}$ International Conference "Methods of Absolute Chronology" May 11-13 $3^{\text {th }}, 2016$, Gliwice-Paniówki, Poland

\title{
OPTICALLY STIMULATED LUMINESCENCE TECHNIQUES APPLIED TO THE DATING OF THE FALL OF METEORITES IN MORASKO
}

\author{
PIOTR MOSKA ${ }^{1}$, WOJCIECH STANKOWSKI ${ }^{2}$ and GRZEGORZ PORĘBA ${ }^{\mathbf{1}}$ \\ ${ }^{1}$ Institute of Physics - Center for Science and Education, Konarskiego 22B str., 44-100 Gliwice, Poland \\ ${ }^{2}$ Institute of Geology, Adam Mickiewicz University, ul. Bogumiła Krygowskiego 12, 61-680 Poznań, Poland
}

Received 16 June 2016

Accepted 17 January 2018

\begin{abstract}
Geological materials used for luminescence dating and associated with the fall of meteorites on the Earth's surface are extremely rare. The Morasko region has gained fame over the past 100 years because of a cosmic catastrophe which took place there. After thousands of years, the remains of a large metal meteorite which fell in this area have been found. In this article, we would like to state whether it is possible, using luminescence methods, to determine the moment when the iron meteorite fell on the surface of the Earth. The material which was analysed consisted of meteorite crust layers - melt/fusion and "semi melt/fusion", including sintered ones, along with the sediments surrounding the meteorite. The final results are connected with four objects of different sizes (large ones and small shrapnel $-261 \mathrm{~kg}, 34 \mathrm{~kg}, 970 \mathrm{~g}$ and $690 \mathrm{~g}$ ). The obtained results show a large discrepancy, which is most likely associated with the problem of resetting the luminescence signal of the tested materials.
\end{abstract}

Keywords: meteorite crusts, OSL dating, Morasko, Poland.

\section{INTRODUCTION}

The Morasko nature-reserve area is a place in Poland where about 1500 elements of iron meteorites with a total mass of about $2000 \mathrm{~kg}$ have been excavated in the last 100 years (Stankowski, 2009; Muszyński et al., 2012). The largest known meteorites in Poland were found in Morasko, with two iron blocks of $164 \mathrm{~kg}$ and $261 \mathrm{~kg}$ being discovered in the last decade. The Morasko meteorites are important because they represent a relatively small class of the asteroid population with iron-nickel bodies. They are also important because of the sparse documentation of this class of objects in the literature.

Corresponding author: P. Moska e-mail: Piotr.Moska@polsl.pl
The Morasko nature reserve is also famous for several impact craters resulting from the fall of meteorites weighing at least several hundred tonnes. Such extraordinary findings have led to an increased interest in the history of this particular area, and several attempts have been made to determine the time when these meteorites fell. In the past, luminescence methods were applied to the material obtained from cleaned meteorites (Stankowski et al., 2007; Stankowski and Bluszcz, 2012). This is due to the assumption that a hot falling meteorite is able to reset the luminescent signal of the minerals which, after its fall, are in direct contact with its surface. We know that the age of the fall of extra-terrestrial matter in this field is also proved by the existence of micro-meteorites and dust with characteristic spherules. Those spherules were also found in the peat bogs in the vicinity of the reserve (e.g. Szlaban near Oborniki Wielkopolskie). The layers of peat 
enriched into the magnetic matter were dated using a radiocarbon method to about 5,000 years BP.

Iron meteorites, when falling into the Earth's atmosphere, fly with an initial speed of approx. $10-20 \mathrm{~km} / \mathrm{s}$. Air resistance causes braking at an altitude of $20-40 \mathrm{~km}$, warming up and shining. During braking, due to the increase in temperature, the total annihilation of such meteoroids usually occurs. But sometimes, in the case of larger objects, the remaining heated parts reach the surface of the Earth. The heated surface of the meteorites is varied by ablative niches with a thin layer/film of fusion. Iron meteorites' falling into the mineral substrate cause either zone variety or thermal effects. On the surface of a meteorite, a non-continuous and very thin fusion layer can remain. The molten meteorite matter, penetrating the encountered meteorite mineral grains, leads to the formation of a spatially limited "semi-fusion unit" - enabling luminescent dating to be conducted due to the existence of heated mineral grains. Apart from the fusion and the "semi-fusion" zone, a commonly continuous sintered layer is created (all structures seen in Fig. 1). In the surrounding mineral strata, a gradient of thermal zeroing occurs around the meteorite. It should be added that the length of the meteorite's time on the ground, in turn, causes the aeration/weathering transformation of the meteorite's contact zone with the surrounding deposits. Therefore, fundamental shell layers of the meteorite are created: fusion-aeration and sintered-aeration. Their thickness and the formation process display considerable variety. The fragmentation of meteorites occurs both above the ground and during the meteorites' fall onto the mineral ground. Therefore, the impact involves crumbs of different sizes and different temperatures of each surface segment. This leads to a non-homogeneous interaction of the meteorites and the sediments at the fall location. The thermal impact directly influences the environment, and, in particular cases, there is also a very shallow penetration of the meteorites' molten matter in the sediments. Both processes result in the generation of sintering layers around the meteorites, and also "semi-fusion" layers in some parts (the encapsulation of mineral grains with the molten material matter of the meteorite). The meteorites' presence in the ground causes weathering transformations of the meteorites' contact zone with the surrounding sediments. Therefore, the generated layers of meteorite crust are fusion-weathering and sintering-weathering. Their thickness and formation are characterised by great diversity.

Recognition of the layers: the right fusion with "semifusion" and sintering was documented in detail with the use of the Scanning Electron Microscopy (SEM) method and an Energy Dispersive Analyser (EDS), performed on a 970 g meteorite (see Fig. 1). This SEM analysis shows that, in these layers, there is a high propensity to properly reset the luminescent signal and the ability to properly use luminescence methods. Data from SEM and EDS (a detailed analysis will be published in the near future in two separate publications: Michalska and WysockaMrozek; Stankowski et al.), for the meteorite crust structure of $970 \mathrm{~g}$, became the basis for selecting luminescence material for all the samples included in this study.
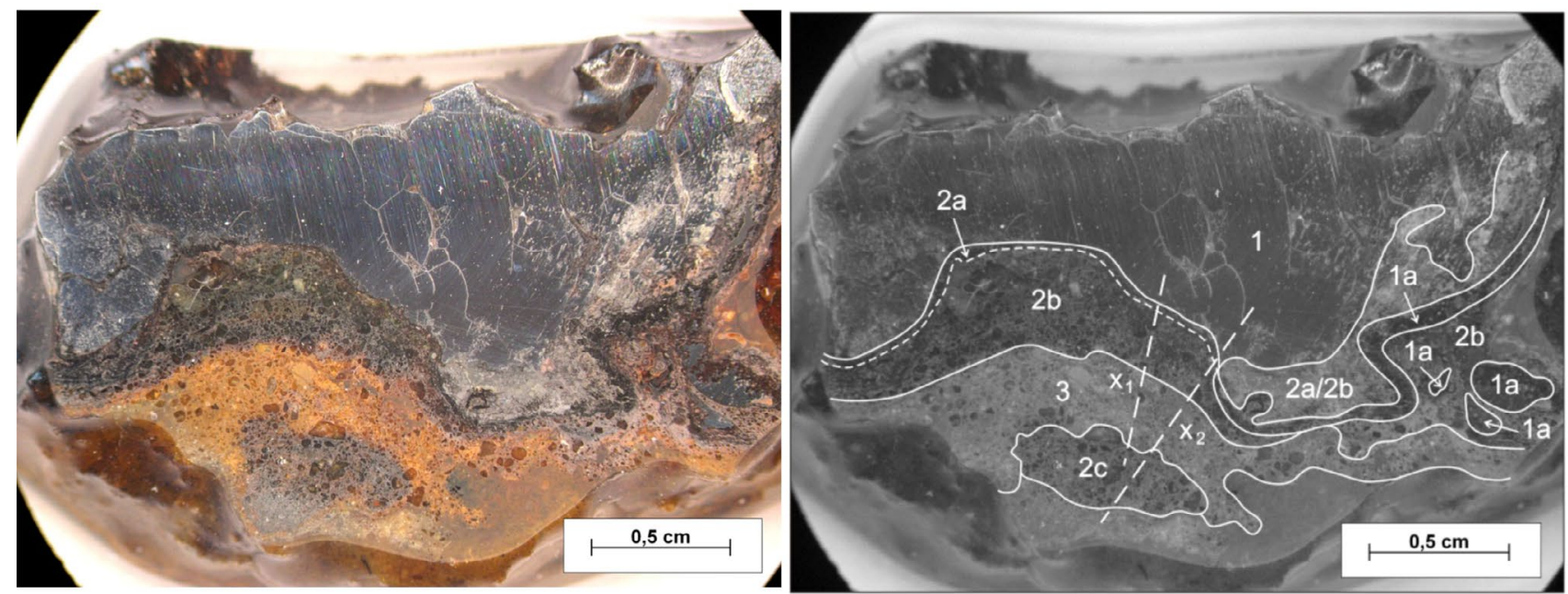

Fig. 1. Photography from the Energy Dispersive Analyser (EDS), performed on a $970 \mathrm{~g}$ meteorite. Characteristic structures can be observed (photo M. Nowak, IG UAM, meteorite cover structure interpretation W. Stankowski). 1 - an iron-nickel alloy; 1a - detach fragments of the alloy; 2a - the molten alloy zone; $2 b$ - the "semi-molten" zone - molten-alloy matter and the grains of material from the fall place; $2 c$ - the tear-away fragments of $2 b ; 3$ - the sintered zone of local matter. 


\section{SITE DESCRIPTION}

The largest iron-meteorite shower in Central Europe occurred in the Morasko meteorite nature reserve near Poznań (Great Poland Lowland/Wielkopolska), (Pilski and Walton 1999). To date, more than $2000 \mathrm{~kg}$ of extraterrestrial iron matter have been officially recognised. It is impossible to determine how many unreported meteorites have also been found. This area is mostly wooded, which makes it harder to search for new findings. All of the found meteorites have a very resistant coating of multiple origins, connected with the thermal and pressure-impact events, and later with the weathering processes. Previous palaeo-environmental studies (morphogenetic, palinologic) predicted the location as well as the time of the Morasko event. Older dates (Stankowski et al., 2007; Stankowski, 2009; Stankowski and Bluszcz, 2012) suggest the event took place about 5000 years ago. The possibility of two meteorite impacts - close in time, at the same location - is very difficult to accept. The Morasko site has been thoroughly described in synthetic publications: Stankowski, 2009; Muszyński et al., 2012, as well as Stankowski, 2015.

\section{LUMINESCENCE DATING}

\section{Sample collection}

For this investigation, 18 samples were used. Nine of them were collected from the strata/ground in a close proximity to the investigated meteorites, and the other nine samples came directly from the meteorite cover. Samples from the strata were collected using standard equipment, and it was easy to collect enough material for further investigation. Collecting samples from meteorites is always more complicated. Fig. 2 presents $34 \mathrm{~kg}$ of meteorite matter after preliminary cleaning, but before both the detailed cleaning of the thin layer of attached clay and the unveiling of the metal crust (Karwowski et al., 2011, samples were collected using this process). Its upper surface was $156 \mathrm{~cm}$ below ground, buried in the colourful Poznan clay (the Miocene Age). Seven investigated samples came directly from the process of direct cleaning, but each sample was obtained from a different place in the investigated meteorites. Samples from smaller meteorites were collected using a similar process of cleaning. After cleaning, some characteristic structures and layers can be observed on the meteorite surface. Recognition of these layers has recently been found by M. Szyszko (see Fig. 1), for the $970 \mathrm{~g}$ meteorite. On this basis, we can distinguish proper fusion, "semi-fusion", and the sintering area. Both the melted and sintered units were initially verified by the EDS technique (performed by D. Michalska and M. Wysocka-Mrozek, IG UAM) and are now undergoing a detailed mineralogical study by A. Duczmal-Czernikiewicz, IG UAM. Proper fusion layers are very thin, and "semi-fusion" layers do not constitute significant parts of the shells either (see Fig. 1). However, their potential role in dating the fall of meteorites seems to be crucial.

Detailed descriptions of the samples used are GdTL 2476-GdTL 2481 from the crust of the $34 \mathrm{~kg}$ meteorite; GdTL 2482 and GdTL 2483 from sediments surrounding the $261 \mathrm{~kg}$ meteorite; GdTL 2484 from the crust of the 690 g meteorite; GdTL 2485, GdTL 2487 and GdTL 2490 from the immediate proximity of the $34 \mathrm{~kg}$ meteorite; GdTL 2486 and GdTL 2488 from a distance of about $5 \mathrm{~cm}$ from the $34 \mathrm{~kg}$ meteorite; GdTL 2489 and GdTL 2491 from a distance of about $10-15 \mathrm{~cm}$ from the $34 \mathrm{~kg}$ meteorite; GdTL 2492 from the crust of the $34 \mathrm{~kg}$ meteorite (another/earlier dating); GdTL 2493 from the crust of the $970 \mathrm{~g}$ meteorite. All this data is also shown in Table 1.

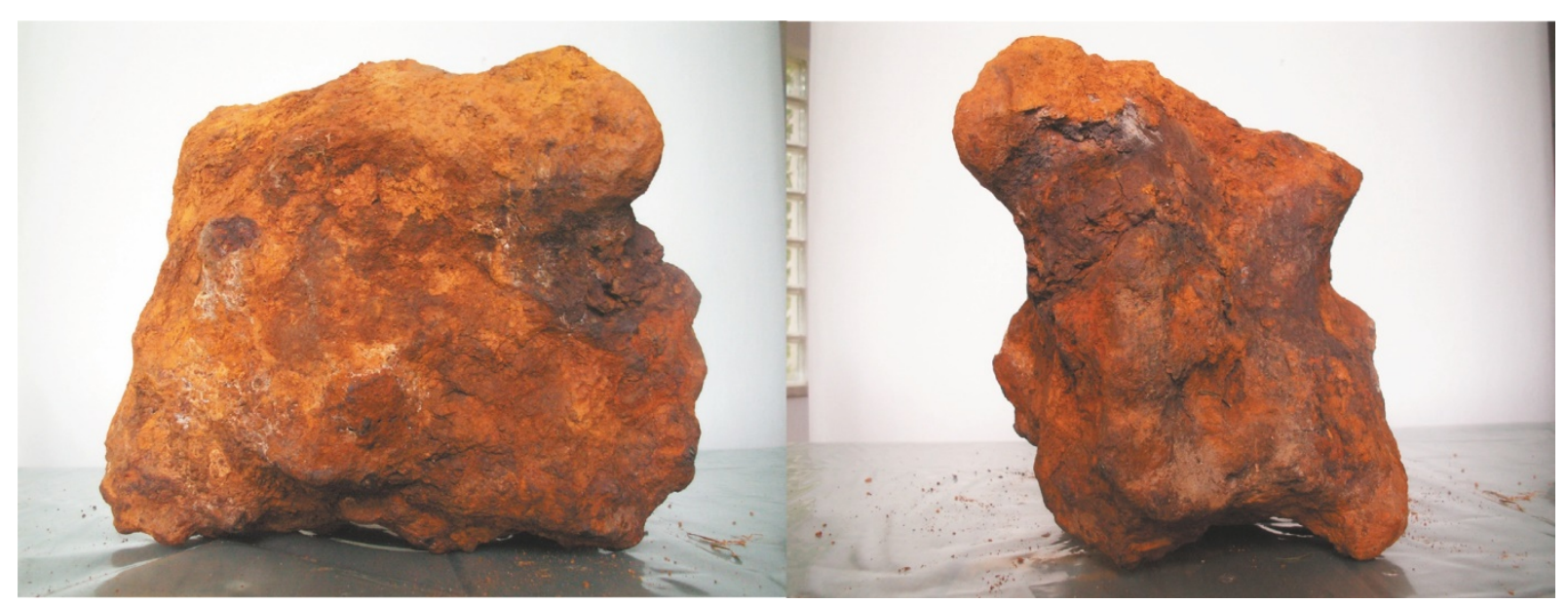

Fig. 2. The most interesting meteorite $(34 \mathrm{~kg})$ used in this investigation, sized $28 \times 24 \times 18 \mathrm{~cm}$. The original photo taken from Karwowski et al. 2011 , with the consent of the editorial office of the Meteorites magazine. 
P. Moska et al.

Table 1. The dose rate results of the analysed samples and their age estimation.

\begin{tabular}{lccc}
\hline Sample name & $\begin{array}{c}\text { Dose rate for age } \\
\text { calculation (Gy/ka) }\end{array}$ & $\begin{array}{c}\text { Equivalent dose } \\
\text { (Gy) }\end{array}$ & $\begin{array}{c}\text { Age (ka) } \\
\text { CAM }\end{array}$ \\
\hline GdTL 2476 (meteorite 34 kg) & $1.27 \pm 0.11$ & $6.9 \pm 0.4$ & $5.4 \pm 0.6$ \\
\hline GdTL 2477 (meteorite 34 kg) & $1.36 \pm 0.12$ & $9.6 \pm 1.0$ & $7.0 \pm 0.9$ \\
\hline GdTL 2478 (meteorite 34 kg) & $1.43 \pm 0.13$ & $29.5 \pm 2.4$ & $20.5 \pm 2.5$ \\
\hline GdTL 2479 (meteorite 34 kg) & $1.42 \pm 0.12$ & $30.5 \pm 3.3$ & $21.4 \pm 2.9$ \\
\hline GdTL 2480 (meteorite 34 kg) & $1.14 \pm 0.10$ & $5.8 \pm 0.4$ & $5.0 \pm 0.5$ \\
\hline GdTL 2481 (meteorite 34 kg) & $1.33 \pm 0.18$ & $11.4 \pm 1.2$ & $8.5 \pm 1.5$ \\
\hline GdTL 2482 (surrounding meteorite 261 kg) & $1.67 \pm 0.17$ & $18.1 \pm 1.6$ & $10.8 \pm 1.5$ \\
\hline GdTL 2483 (surrounding meteorite 261 kg) & $1.58 \pm 0.15$ & $9.4 \pm 1.1$ & $5.9 \pm 0.9$ \\
\hline GdTL 2484 (meteorite 690 g) & $1.12 \pm 0.11$ & $24.9 \pm 2.0$ & $22.2 \pm 2.9$ \\
\hline GdTL 2485 (surrounding meteorite 34 kg) & $2.40 \pm 0.19$ & $8.5 \pm 1.0$ & $3.5 \pm 0.5$ \\
\hline GdTL 2486 (surrounding meteorite 34 kg) & $3.21 \pm 0.24$ & $17.0 \pm 1.2$ & $5.2 \pm 0.5$ \\
\hline GdTL 2487 (surrounding meteorite 34 kg) & $3.79 \pm 0.26$ & $14.7 \pm 1.6$ & $3.8 \pm 0.5$ \\
\hline GdTL 2488 (surrounding meteorite 34 kg) & $4.37 \pm 0.30$ & $11.3 \pm 0.5$ & $2.5 \pm 0.2$ \\
\hline GdTL 2489 (surrounding meteorite 34 kg) & $3.84 \pm 0.29$ & $59.5 \pm 4.4$ & $15.4 \pm 1.6$ \\
\hline GdTL 2490 (surrounding meteorite 34 kg) & $2.22 \pm 0.17$ & $6.8 \pm 0.7$ & $3.0 \pm 0.4$ \\
\hline GdTL 2491 (surrounding meteorite 34 kg) & $3.17 \pm 0.24$ & $48.7 \pm 4.1$ & $15.3 \pm 1.7$ \\
\hline GdTL 2492 (meteorite 34 kg) & $1.04 \pm 0.10$ & $79.0 \pm 8.0$ & $75.9 \pm 10.7$ \\
\hline GdTL 2493 (meteorite 970 g) & $1.34 \pm 0.13$ & $37.2 \pm 1.9$ & $27.6 \pm 3.0$ \\
\hline
\end{tabular}

\section{Dose rate estimation}

In order to determine the period in which the luminescence signal was reset the previous time, it is necessary to determine the following two independent parameters: the dose rate (Gy/year) and the equivalent dose (Gy). The final age result is always a quotient of these parameters, according to the simple equation presented below.

$\operatorname{age}($ years $)=\frac{\text { equivalent_dose }(G y)}{\text { dose_rate }(\text { Gy } / \text { year })}$

In the case of meteorite fusion crusts, which are nonstandard samples, obtaining the appropriate material for the luminescent analysis is difficult, yet possible. It should also be noted that, from the point of view of achieving the final results, the greatest problem which we have exposed was the correct definition of the annual dose rate. The dose rate is the amount of energy absorbed per year from radiation in the environment surrounding the measured material, and can be derived by directly measuring the amount of radioactivity, or by a chemical analysis of the surrounding material. Usually, in order to determine the dose rate, high-resolution gamma spectrometry or mass spectrometry (ICP-MS) are used.

To derive the dose rate for meteorites as well as for sediment samples, high-resolution gamma spectrometry, equipped with an HPGe gamma ray detector manufactured by CANBERRA, was used. This equipment measured the concentration in the U-238 series, the Th-232 series, and the concentration of K-40. Besides this, the activity of the Cs-137 artificial isotope was measured in samples to recognise modern sediment mixing. The main source of this isotope is provided by nuclear weapon tests and, additionally, by the nuclear power plant accident in Chernobyl. The samples for measurement were dried, homogenised and placed in measurement containers. After being placed in the measurement containers, the samples were stored for about 4 weeks to ensure equilibrium between gaseous ${ }^{222} \mathrm{Rn}$ and ${ }^{226} \mathrm{Ra}$ in the ${ }^{238} \mathrm{U}$ decay chain. Typical counting time was about $80 \mathrm{ks}$. The resolution of the detector was about $1.8 \mathrm{keV}$ and the relative efficiency was $35 \%$. As a standard, materials manufactured by IAEA (IAEA-375, RGU, RGTh, RGK) were used. Additionally, a reference material of IAEA-385 was used to check the calibration quality. To calculate the U-238 content, the following gamma lines were taken: $295.1 \mathrm{keV}$ (Pb-214), 352.0 keV (Pb-214), 609.3 keV (Bi-214) and $1120.3 \mathrm{keV}(\mathrm{Bi}-214)$. In the case of the Th-232 decay chain the following gamma lines were considered: $583.0 \mathrm{keV}$ (TL-208), $911.2 \mathrm{keV}$ (Ac-228) and $2614.4 \mathrm{keV}$ (Tl-208). To calculate the K-40 content the $1460.8 \mathrm{keV}$ gamma line was taken. To calculate the Cs- 137 content the $661.7 \mathrm{keV}$ gamma line was taken. The activities of radioisotopes were converted into dose rates by using the conversion factors described by Guerin et al. (2011). The dry dose rates (Adamiec and Aitken, 1998, Guerin et al., 2011) were adjusted for water content, following Aitken (1985). We assumed that the average water content was no higher than $15 \%$ and consequently used a value of $10 \pm 5 \%$ for further calculations. The cosmic ray dose rate at the site follows the calculations suggested by Prescott and Stephan (1982). The results of radionuclide analysis for samples and the surrounding sediment, as well as the results of the dose rate calculation, are summarised in Table 1. In the case of a dosimetry calculation of the meteorite samples, it is necessary to make a more detailed consideration based on the principle of superposition to be used, and especially to determine the annual dose from gamma rays, which have long 
ranges in the soil. The specific geometry of meteorites has to be taken into account, as the meteorites were approximated as relevant spheres with diameters depending on the meteorite mass. To calculate the dose for coating (sinter) layers, it was assumed that meteorites were made from iron, and there was no activity inside iron meteorites (Stankowski, 2009). The total dose rate is the sum of alpha, beta, gamma and cosmic dose rates. In the case of the meteorite sinter layer, the activity of the sediment was also considered. This was similar to heated stones (Khasawneh et al., 2015) or to bricks (Chruścinska et al., 2014).

\section{Equivalent dose calculation}

For OSL measurements, coarse grains and fine grains of quartz were extracted from the samples. Coarsegrained quartz was extracted from soil samples from meteorite environments, and fine-grained quartz was extracted from the meteorite samples. Both fractions were treated with $20 \%$ hydrochloric acid $(\mathrm{HCl})$ and $20 \%$ hydrogen peroxide $\left(\mathrm{H}_{2} \mathrm{O}_{2}\right)$. The last step was to add hexafluorosilicic acid $\left(\mathrm{H}_{2} \mathrm{SiF}_{6}\right)$ for fine grains and hydrofluoric acid (HF) for coarse-grained quartz.

All OSL measurements were performed using an automated Daybreak 2200 TL/OSL reader (Bortolot, 2000). This reader uses the Hoya U-340 optical filter with blue diodes $(470 \pm 4 \mathrm{~nm})$, delivering about $60 \mathrm{~mW} / \mathrm{cm}^{2}$ at the sample position.

Laboratory irradiations were performed using a calibrated ${ }^{90} \mathrm{Sr}{ }^{90} \mathrm{Y}$ beta source mounted onto the reader, delivering a dose rate of $2.8 \mathrm{~Gy} / \mathrm{min}$. Equivalent doses were determined using the single-aliquot regenerativedose (SAR) protocol (Murray and Wintle, 2000). The OSL SAR protocol, which was used in our measurements, contains the following steps.

1) Irradiation with the regenerative beta dose $D_{i}$

2) Preheating at a temperature of $260^{\circ} \mathrm{C}$ for $10 \mathrm{~s}$

3) Blue-light stimulation at a temperature of $125^{\circ} \mathrm{C}$ for $100 \mathrm{~s}$

4) Irradiation with the test dose $D_{t}(10 \%$ of the natural dose, but not less than $5 \mathrm{~Gy}$ )

5) Cut-heat at a temperature of $220^{\circ} \mathrm{C}$

6) Blue-light stimulation at a temperature of $125^{\circ} \mathrm{C}$ for $100 \mathrm{~s}$.

For an equivalent dose calculation, the first second of the signal was used and the background was estimated from the last 10 seconds. The SAR dose response curves were best represented by a single saturating exponential. A dose recovery test was carried out for both samples, performed under the standard SAR conditions. For each sample, 5 different aliquots were used. Subsequently, all aliquots were bleached with blue light for $100 \mathrm{~s}$ (at room temperature) and after a pause of $10000 \mathrm{~s}$ were bleached for another $100 \mathrm{~s}$. After the bleaching, a laboratory dose with a value similar to the equivalent dose of each sample was administered and measured using the SAR protocol.
The results of the obtained dose recovery ratio were close to unity.

Equivalent doses were determined using the singlealiquot regenerative-dose (SAR) protocol (Murray and Wintle, 2000), and OSL age results were obtained using the Central Age Model (CAM) (Galbraith et al., 1999), shown as the relative probability density functions (Berger, 2010). The distributions of age values were also presented as relative probability density functions (Berger, 2010).

\section{DISCUSSION}

In the research conducted for over a dozen years by Stankowski, associated with the reliable determination of the impact time of the Morasko meteorites, significant progress has taken place in terms of the ability to employ luminescence methods. The most important change was the use of materials from one and the same meteorite, but collected from different places at the surface. All samples from the meteorite weighing $34 \mathrm{~kg}$ contain a thin layer of sediment which was adhered to the metal surface, along with the material which comes from the molten or semimolten zone. This material, according to our knowledge, was heated to high temperatures in the past, during the fall of the heated iron meteorite in this place. In the ideal case, all the investigated samples would be bleached to a residual level at the same time in the past, so the obtained results should be very similar. These results are presented in Table 1, and in Fig. 3, where the distribution of ages is shown as relative probability. The large spread of ages from $5 \mathrm{ka}$ to $76 \mathrm{ka}$ indicates that in the past the resetting of the luminescence signal was different and depended on the location on the meteorite. It is very difficult to explain why two out of seven similar samples gave ages of about $5 \mathrm{ka}$ (GdTL 2476 and GdTL 2480), whereas the next two results were about 7-8 ka (GdTL 2477 and 2481), and the last two results were about $20 \mathrm{ka}$ (GDTL 2478 and GdTL 2479). The result for sample GdTL 2492 was completely unexpected, because $76 \mathrm{ka}$ is much higher than all the other investigated samples. In analysing all the results obtained for the $34 \mathrm{~kg}$ meteorite as one set of data, we can create Fig. 4, where the density probability function is presented for all the obtained aliquots. Despite the fact that we are dealing with a wide distribution, a clear maximum is created between 4-6 ka. This might suggest that, during this time we have the highest probability that the investigated material was bleached. In analysing Fig. 4, it is possible to obtain the most probable time of resetting the luminescence signal (meteorite fall) for the age about $5.2 \pm 0.3 \mathrm{ka}$. According to Karwowski et al., 2011, the $34 \mathrm{~kg}$ meteorite was found at a depth of about 1.5 metres below the current surface of the Neogene sediments of a geological age of a few million years. The samples collected from the closest environment of this meteorite from the Neogene sediments indicate that these sediments were exposed to sunlight or high temperatures during the 

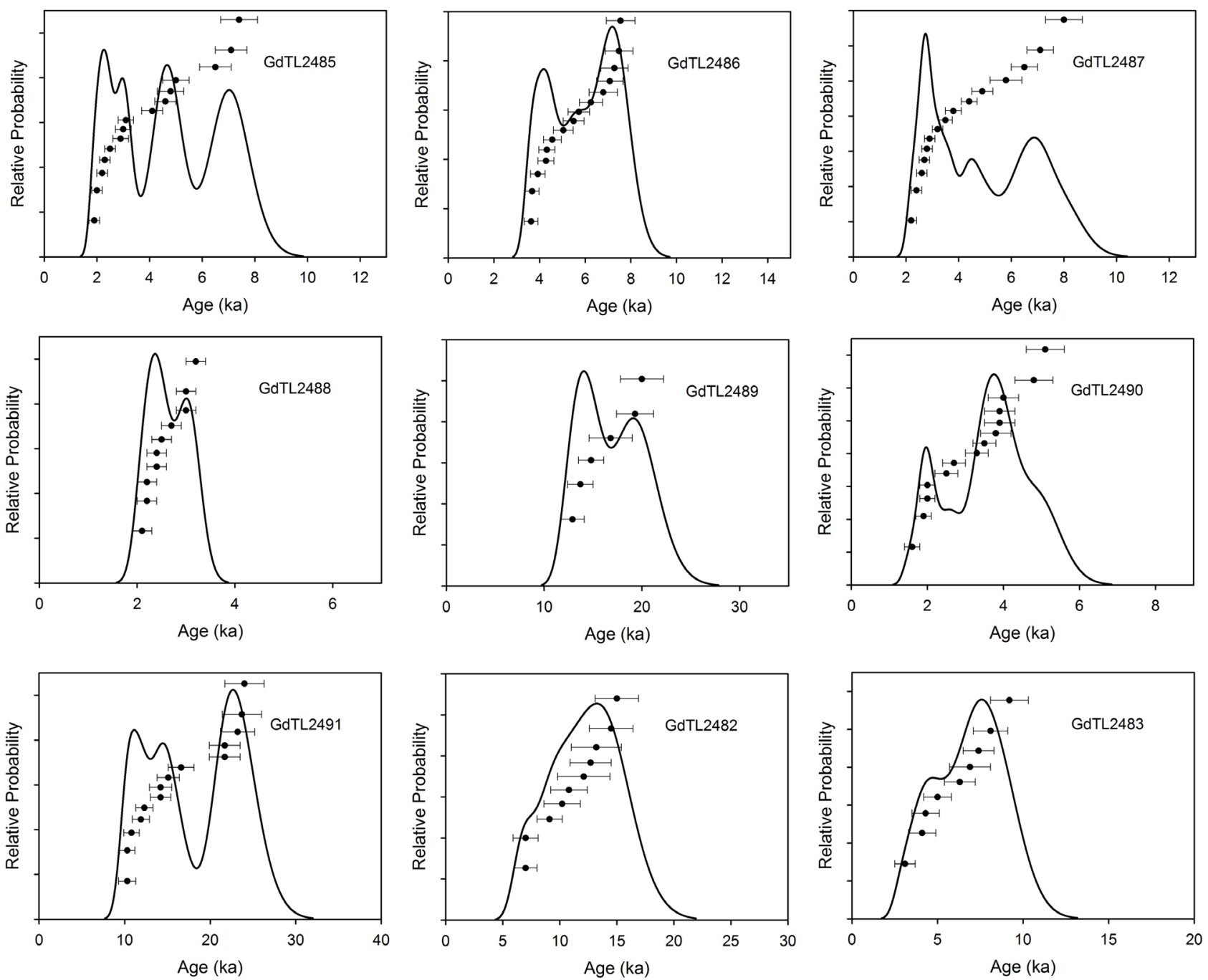

Fig. 3. The distribution of ages as relative probability-density functions (Berger, 2010) for the investigated $34 \mathrm{~kg}$ meteorite samples.

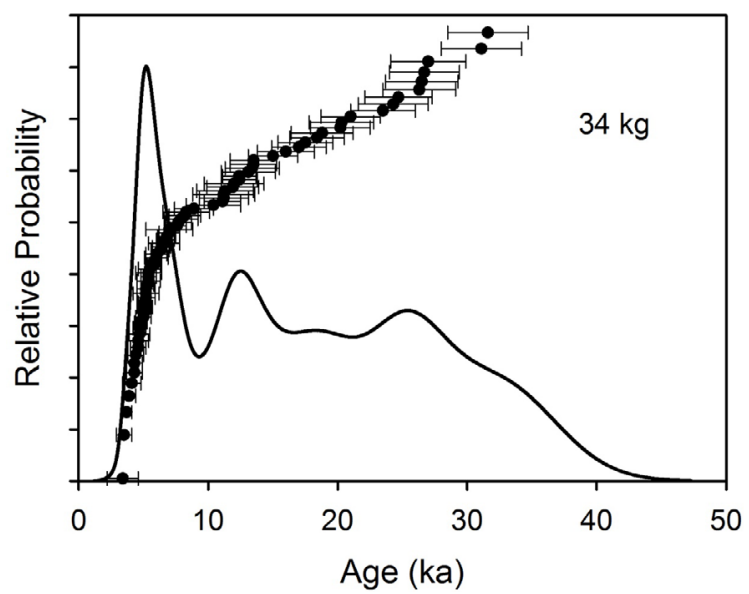

Fig. 4. The distribution of ages as relative probability-density functions (Berger, 2010) for the investigated $34 \mathrm{~kg}$ meteorite samples put together on one graph. last $15 \mathrm{ka}$ or less (Fig. 5 and Table 1). This range of obtained results correlates very well with the age range obtained for the meteorite. This time range also includes the results from the sediments from the closest proximity of the $261 \mathrm{~kg}$ meteorite (GdTL 2482 and GdTL 2483). The samples from small meteorites (690 g, GdTL 2484 and 970 g, GdTL 2493), associated with Quaternary sediments, provide the dates exceeding the geological age of the youngest glacial deposits in the Morasko area. This suggests the incomplete zeroing of the material originating from older glacial deposits, included in the sintering meteorite crust.

It is inevitable to refer to the previous luminescence analyses conducted more than 10 years ago by Stankowski and Bluszcz (Stankowski et al., 2007; Stankowski and Bluszcz, 2012). Sediments which were found in the biggest impact craters in Morasko were investigated using optically stimulated luminescence and radiocarbon da- 

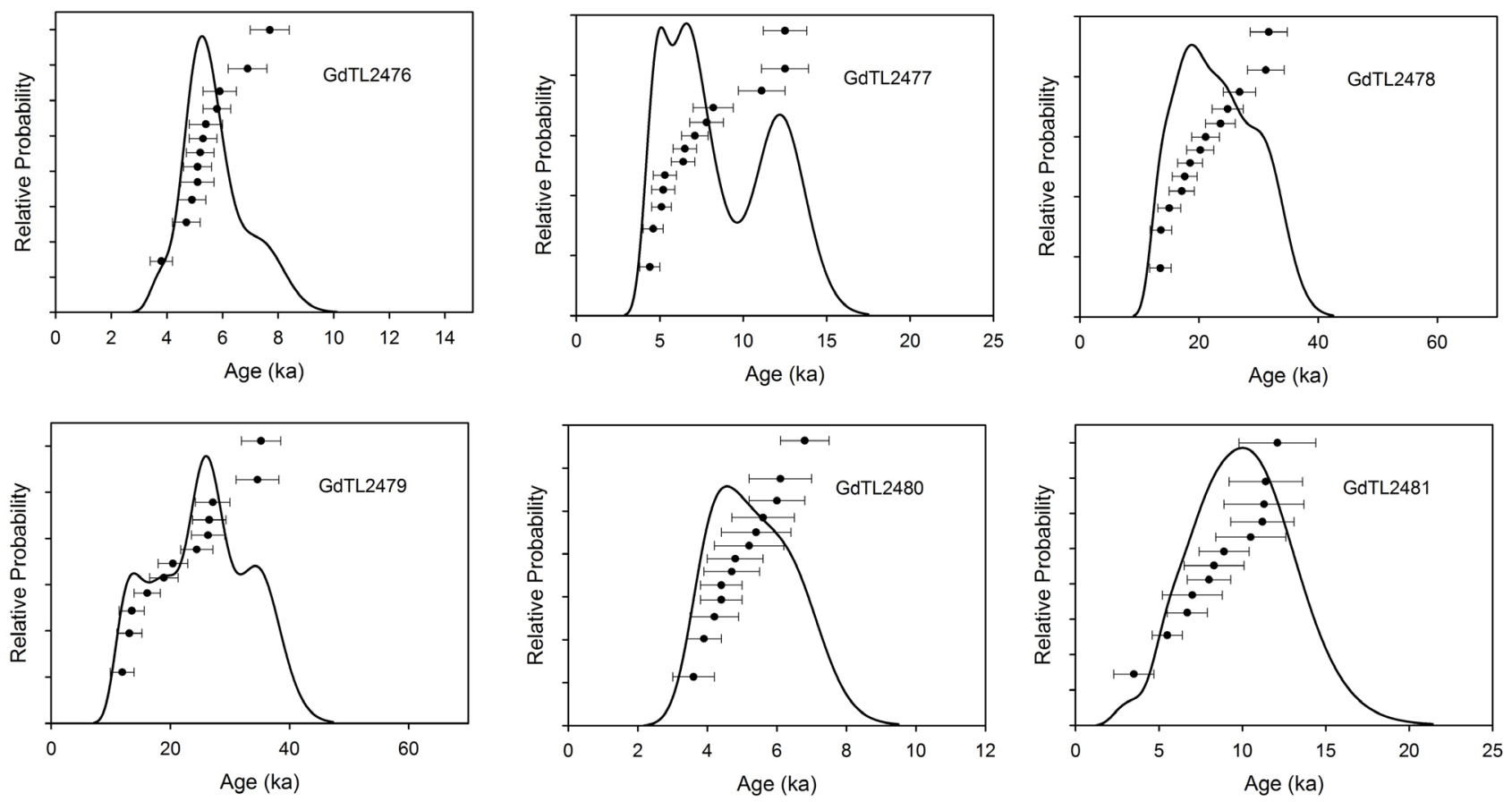

Fig. 5. The distribution of ages as relative probability-density functions (Berger, 2010) for the investigated soil samples.

ting. Luminescence investigation has shown that the range of the obtained results is vast - from a few thousand years to even more than $100 \mathrm{ka}$. In contrast to the luminescence investigation, the results for radiocarbon dating are much more consistent and indicate the time of the meteorite fall in Morasko as about 5 ka BP. For radiocarbon dating, samples of the organic material from characteristic layers containing spherules (elements which entered into the sediment due to the fall of a large meteorite) were collected, so the obtained results are a reliable reference for our investigation. Treating these results as a point of reference, we can also try to assert whether it is possible to obtain reliable luminescence results from the samples collected from the surface of the investigated meteorites. Based on all the analyses connected with our investigation, we can say that it is not possible to obtain reliable luminescence results for the materials which were available on the meteorite surface, due to the large discrepancies of the obtained ages in the analysed samples.

\section{CONCLUSION}

The reflections on the possibility of determining the time of the meteorite fall in Morasko, as presented here, indicate that this problem is complex and difficult to be interpreted using luminescence methods. Despite the fact that 7 independent samples were collected from the same meteorite, the obtained results were far from those expected. Most probably, this might have been related to the large temperature differences of individual pieces of the fragmented meteorite (heated surface and cold interior). Of course, this is associated with a significant discrepancy in the obtained results. However, a reference can be made to Fig. 4, where the most probable age of the zeroing luminescence signal is in the period of about $5 \mathrm{ka}$ in the past. Given that, we can imply that five thousand years ago probably defines the lowest possible age of the meteorite fall. We cannot deny the fact that the process of bleaching the luminescence signal was uneven on the meteorite surface of the, which means that the basic assumption of the luminescence method was not fulfilled. Because the obtained age depends on the place of the sample collection on the meteorite surface, it is possible to set the most probable date of the meteorite fall, only because many samples were collected. With a single meteorite sample, it is impossible to reliably estimate the age of its fall.

\section{ACKNOWLEDGMENTS}

The authors express their cordial thanks to Mateusz Szyszko - a candidate for a PhD at the Institute of Geology UAM, for finding and offering the meteorites for investigation. 


\section{REFERENCES}

Adamiec G and Aitken MJ, 1998. Dose-rate conversion factors: update. Ancient TL 16: 37-50.

Aitken MJ, 1985. Thermoluminescence Dating. Academic Press, London, $359 \mathrm{pp}$.

Berger GW, 2010. An alternate form of probability- distribution plot for $\mathrm{D}_{\mathrm{e}}$ values. Antient TL 28: 11-22.

Bortolot VJ, 2000. A new modular high capacity OSL reader system. Radiation Measurements 32: 751-757, DOI 10.1016/S13504487(00)00038-X.

Chruścińska A, Cicha A, Kijek N, Palczewski P, Przegięta K and Sulkowska-Tuszyńska K, 2014. Luminescence dating of bricks from the gothic Saint James church in Torun. Geochronometria 41: 352-360, DOI 10.2478/s13386-013-0165-y.

Galbraith RF, Roberts RG, Laslett GM, Yoshida H and Olley JM, 1999. Optical dating of single and multiple grains of quartz from Jinminum Rock Shelter, Northern Australia. Part I, experimental design and statistical models. Archaeometry 41: 1835-1857, DOI 10.1111/j.1475-4754.1999.tb00987.x.

Guerin G, Mercier N and Adamiec G, 2011. Dose-rate conversion factors: update. Ancient TL 29: 5-8.

Karwowski Ł, Pilski A, Muszyński A, Arnold S, Notkin G and Gurdziel A, 2011. New finds in the Morasko meteorite preserve, Poland. Meteorites 1(1): 21-28.

Khasawneh S, Murray A, Bonatz D and Freiesleben T, 2015. Testing the application of post IR IRSL dating to Iron- and Viking-age ceramics and heated stones from Denmark. Quaternary Geochronology 30: 386-391, DOI 10.1016/j.quageo.2015.05.014.

Murray AS and Wintle AG, 2000. Luminescence dating of quartz using an improved single aliquot regenerative-dose protocol. Radiation Measurements 32: 57-70, DOI 10.1016/S1350-4487(99)00253-X.

Muszyński A, Kryza R, Karwowski Ł, Pilski AS and Muszyńska J, 2012. The largest iron meteorite shower in Central Europe. Bogucki Wydawnictwo Naukowe, Poznań, 109 pp.

Pilski AS and Walton W, 1999. Morasko - the largest European iron meteorite shower. Meteorite 5: 27-28.

Prescott JR and Stephan LG, 1982. The contribution of cosmic radiation to the environmental dose for thermoluminescence dating. Latitude, altitude and depth dependencies. TLS II-1, 16-25.

Stankowski WTJ, Raukas A, Bluszcz A and Fedorowicz S, 2007. Luminescence dating of the Morasko (Poland), Kaali, Ilumetsa and Tsoorikmae (Estonia) meteoryt craters. Geochronometria 28: 2529, DOI 10.2478/v10003-007-0031-0.

Stankowski WTJ, 2009. Morasko Meteorite, a curiosity of the Poznan' region, Time and results of the fall. UAM, Poznań, $94 \mathrm{pp}$.

Stankowski WTJ and Bluszcz A, 2012. Luminescence Dating as Comparative Data to Radiocarbon Age Estimation of Morsko Spherical Depressions. Radiometric Dating, (ed.) D.Michalska-Nawrocka. INTECHOPEN.COM, Printed In Croatia, pp.115-126.

Stankowski WTJ, 2015. The extraterrestrial matter falls in west-central Poland (Great Poland Lowland); historical and geological data. Acta Geologica Polonica 65(2): 265-270. 